\section{Neuromuscular effects of vecuronium and neostigmine in Montreal and Paris}

Y. Salib MD,* J. Frossard MD, $\nmid$ B. Plaud MD, $\uparrow$

B. Debaene MD, $\dagger$ C. Meistelman MD, $\nmid$ F. Donati PhD MD*
The potency of vecuronium was reported to be greater in Montréal than in Paris. This study was designed to determine whether there were differences in onset, duration, and reversibility with neostigmine between both centres. Twenty $A S A$ I or II adults (ten men, ten women), aged 18-65 yr were studied in each of the two cities, during a standard thiopentonefentanyl-nitrous oxide (60-70\%) - isoflurane $0.5 \%$ end-tidal anaesthetic. Train-of-four stimulation was applied every $20 \mathrm{sec}$ to the ulnar nerve at the wrist and the force of contraction of the adductor pollicis muscle was measured. Vecuronium, 0.1 $\mathrm{mg} \cdot \mathrm{kg}^{-1}$, was given as a bolus, and neostigmine, 0.04 $\mathrm{mg} \cdot \mathrm{kg}^{-1}$, was administered, with atropine $0.02 \mathrm{mg} \cdot \mathrm{kg}^{-1}$, at $25 \%$ first twitch height recovery. Onset time to maximum blockade was (mean $\pm S D$ ) $3.9 \pm 1.3 \mathrm{~min}$ in Paris vs $4.5 \pm 1.3$ min in Montréal (NS). Duration from injection to $25 \%$ first twitch recovery was shorter $(28.5 \pm 6.8 \mathrm{~min})$ in Paris than in Montréal (39.1 $\pm 7.3 \mathrm{~min})(P<0.0001)$. Time from injection of neostigmine to a train-of-four ratio of $70 \%$ was not different in Paris (6.3 $\pm 2.2 \mathrm{~min}$ ) from Montréal ( $5.6 \pm 1.9 \mathrm{~min})$. It is concluded that the duration of an "intubating" dose of vecuronium is longer in Montréal, but, when given at $25 \%$ first twitch recovery, neostigmine has the same efficacy in Montréal as in Paris.

Le vécuronium est plus puissant à Montréal qu'à Paris. On $a$ voulu déterminer si l'on retrouvait des différences de temps d'installation, de durée et de neutralisation avec la néostigmine

\section{Key words}

ANTAGONISTS, NEUROMUSCULAR RELAXANTS:

neostigmine;

MONITORING: neuromuscular duration, train-of-four; NEUROMUSCULAR RELAXANTS: vecuronium.

From the *Departments of Anaesthesia, Royal Victoria Hospital and McGill University, Montreal, Quebec, and †Service d'anesthésie, Institut Gustave Roussy, Villejuif, France.

Address correspondence to: Dr. François Donati, Département d'anesthésie-réanimation, Hôtel-Dieu de Montréal, 3840, rue Saint-Urbain, Montréal, Québec H2W 1T8.

Accepted for publication 5th June, 1994. entre les deux endroits. Dans chaque ville, on a recruté vingt adultes (dix hommes et dix femmes), agés de 18 à 65 ans, et anesthésiés au thiopentone, protoxyde d'azote (60-70\%) et isoflurane $(0.5 \%$ télé-expiratoire). On a stimulé le nerf cubital toutes les $20 \mathrm{sec}$ en utilisant le train-de-quatre et on a mesuré la force de contraction de l'adducteur du pouce. Une dose de $0,1 \mathrm{mg} \cdot \mathrm{kg}^{-1}$ de vécuronium a été injectée, suivie de néostigmine, $0,04 \mathrm{mg} \cdot \mathrm{kg}^{-1}$ et d'atropine, $0,02 \mathrm{mg} \cdot \mathrm{kg}^{-1}$ lorsque le premier élément du train-de-quatre récupérait à $25 \%$ de sa valeur initiale. Lintervalle entre linjection et le bloc maximum était de (moyenne $\pm E T$ ) 3,9 $\pm 1,3$ min à Paris et 4,5 $\pm 1,3$ min à Montréal (NS). La durée d'action, c'est-à-dire le temps entre linjection de vécuronium et la récupération de $25 \%$, était plus courte à Paris $(28,5 \pm 6,8 \mathrm{~min})$ qu'à Montréal $(39,1 \pm$ 7,3 min) $(P<0,0001)$. Après administration de néostigmine, il fallait 6,3 $\pm 2,2$ min à Paris pour atteindre un rapport quatrième: première réponse de $70 \%$, et 5,6 $\pm 1,9$ min à Montréal (NS). On en conclut que la durée d'une dose "dintubation" est plus longue à Montréal, mais que si la néostigmine est donnée quand la récupération atteint $25 \%$, elle est tout aussi efficace à Montréal quà Paris.

In 1969, Katz et al. ${ }^{1}$ reported that the maximum blockade attained after a single dose of d-tubocurarine or succinylcholine was greater and the duration of action was longer in New York than in London. The study was performed before dose-response techniques became common practice in the evaluation of muscle relaxants, and before a standard mode of stimulation, the train-of-four, ${ }^{2}$ was introduced into clinical use and research.

Recently, Fiset et al. ${ }^{3}$ performed another transatlantic study, and compared the dose-response curves for vecuronium between Montréal and Paris. In spite of similar demographic data in both centres and an identical anaesthetic and neuromuscular technique, the Paris doseresponse curve was shifted to the right by $30 \%$, that is, vecuronium was more potent in Montréal. The difference could not be explained by differences in age, sex, weight or body habitus, because these variables were similar in both cities. Disposition of the drug probably had little effect on these differences, because dose-response data are 
obtained from twitch depression obtained shortly after drug administration. Thus, it is possible that the transatlantic differences might be due to a different relationship between plasma concentration and twitch height, i.e., a pharmacodynamic difference.

These data do not necessarily imply that onset is longer and duration is shorter in Paris than in Montréal, because pharmacokinetic differences could be present. It is also unclear whether differences in sensitivity extend beyond the dose range $\left(0.02-0.04 \mathrm{mg} \cdot \mathrm{kg}^{-1}\right)$ used for doseresponse data, and also apply to intubating doses $\left(0.1-0.15 \mathrm{mg} \cdot \mathrm{kg}^{-1}\right)$. In addition, differences in sensitivity to vecuronium could also imply differences in the response to neostigmine. Therefore, this study was designed to examine the neuromuscular effects of clinically useful doses of vecuronium and neostigmine under identical anaesthetic conditions in Montréal and in Paris.

\section{Methods}

The protocol was approved by the Ethics Committee at the Royal Victoria Hospital in Montréal, and at Institut Gustave Roussy in Villejuif, located in the suburbs of Paris, France. At each centre, an equal number of men and women, ASA status I or II, aged 18-65 yr, and scheduled for elective surgery requiring tracheal intubation, were entered in the study. There was a total of 40 patients, 20 from each location. Exclusion criteria were ASA status III or greater, emergency surgery, anticipated difficulty with the airway, deviation from ideal body weight by more than $30 \%$, renal, hepatic or neuromuscular disease, and acute or chronic ingestion of drugs for which an interaction with neuromuscular function is known or suspected. Premedication, when given, consisted of an opioid or a benzodiazepine, and was at the discretion of the anaesthetist.

In the operating theatre, standard monitoring equipment was used and consisted of ECG, pulse oximetry, non-invasive arterial blood pressure measurement, endtidal $\mathrm{PCO}_{2}$, inspired oxygen fraction and end-tidal vapour pressure. Surface electrodes were applied to the ulnar nerve at the wrist and the force of contraction of the adductor pollicis muscle was measured with a Grass FT10 transducer (Grass Instruments, Quincy, Mass, USA) in Montréal and a Bioindustry Curamètre transducer (Bioindustry, Boulogne-sur-Mer, France) in Paris. Anaesthesia was induced with thiopentone, $5-7 \mathrm{mg} \cdot \mathrm{kg}^{-1}$, and fentanyl, $1-2 \mu \mathrm{g} \cdot \mathrm{kg}^{-1}, i$. Then, the lungs were ventilated manually with $100 \%$ oxygen. Supra-maximal train-offour stimulation was applied after loss of consciousness, using a Datex NMT-221 (Datex, Helsinki, Finland) in Montreal, and a Bioindustry Curamètre in Paris, after the calibration of the stimulators was made. Within two minutes after calibration was obtained, vecuronium, 0.1 $\mathrm{mg} \cdot \mathrm{kg}^{-1}$ was injected $\dot{i}$ as a rapid bolus. Tracheal intubation was performed when maximum blockade was obtained. Then, mechanical ventilation was initiated, and adjusted to keep end-tidal $\mathrm{PCO}_{2}$ in the range 30-35 mmHg.

Anaesthesia was maintained with nitrous oxide (60-70\%), isoflurane, $0.5 \%$ end-tidal concentration, and fentanyl, $1-2 \mu \mathrm{g} \cdot \mathrm{kg}^{-1}$ as required. No incremental doses of vecuronium were administered. When first twitch height $\left(\mathrm{T}_{1}\right)$ in the train-of-four reached $25 \%$ of prevecuronium control, neostigmine, $0.04 \mathrm{mg} \cdot \mathrm{kg}^{-1}$, with atropine, $0.02 \mathrm{mg} \cdot \mathrm{kg}^{-1}$ was injected $i$. Neuromuscular blockade was monitored for an additional ten minutes, during which time the end-tidal nitrous oxide and isoflurane concentrations were maintained constant.

Times from vecuronium injection to $50 \%, 95 \%$ and maximum $\mathrm{T}_{1}$ blockade were recorded. Times to $50 \%$ and 95\% were interpolated if necessary. Maximum blockade was considered to occur at the first of three consecutive equal $\mathrm{T}_{1}$ responses. With $100 \%$ blockade, maximum blockade was considered to take place at the first undetectable train-of-four response. Maximum blockade, duration from injection to $5 \%$ and $25 \% \mathrm{~T}_{1}$ recovery, and duration from $5 \%$ to $25 \%$ were measured. The train-offour ratio $\left(\mathrm{T}_{4} / \mathrm{T}_{\mathrm{l}}\right)$ was measured at $0,2,5$ and $10 \mathrm{~min}$ after neostigmine administration. In addition, the time from injection of neostigmine to $T_{4} / T_{1}=70 \%$ was noted. All measurements were recorded at each site and the tracings were subsequently reviewed by a single investigator (FD). Results are presented as mean \pm standard deviation (SD) and range as indices of dispersion. A Student's $\mathrm{t}$ test was applied to comparisons between the two sites and differences associated with a $P$ value $<0.05$ were considered to be significantly different.

\section{Results}

Demographic data are presented in Table I. There were no differences in sex distribution, height and weight between both centres.

Onset times to $50 \%, 95 \%$ or maximum blockade were not different between both cities (Table II). Maximum blockade was $100 \%$ in all Montréal patients, and in 18 (95\%) patients in Paris. The remaining two patients had blockades of 98 and $99 \%$, respectively.

Times to $5 \%$ and $25 \% \mathrm{~T}_{1}$ recovery were respectively 10.8 and $10.6 \mathrm{~min}$ longer in Montréal $(P<0.0001)$, but the recovery rate $\left(5-25 \% \mathrm{~T}_{1}\right)$ was the same at both sites (Table III).

The train-of-four ratios before, and 2,5 and $10 \mathrm{~min}$ after neostigmine administration were similar in both cities. Mean time from injection of neostigmine to $T_{4} / T_{1}$ $=70 \%$ was approximately six minutes in both centres (Table IV). 
TABLE I Demographic data (mean \pm SD)

\begin{tabular}{lcc}
\hline & Montréal & Paris \\
\hline Sex (M/F) & $10 / 10$ & $10 / 10$ \\
Age (yr) & $39 \pm 12$ & $45 \pm 13$ \\
Weight (kg) & $69 \pm 13$ & $64 \pm 12$ \\
Height (cm) & $167 \pm 2$ & $165 \pm 2$ \\
\hline
\end{tabular}

TABLE II Onset data (mean $\pm \mathrm{SD}$ )

\begin{tabular}{lll}
\hline Time from injection to ... (min) & Montréal & Paris \\
\hline $50 \% \mathrm{~T}_{1}$ block & $1.94 \pm 0.53$ & $1.61 \pm 0.60$ \\
$95 \% \mathrm{~T}_{1}$ block & $3.39 \pm 0.67$ & $3.10 \pm 0.73$ \\
$100 \% \mathrm{~T}_{1}$ block & $4.47 \pm 1.28$ & $3.93 \pm 1.29$ \\
\hline
\end{tabular}

TABLE III Duration of effect (mean \pm SD) (range)

\begin{tabular}{lcl}
\hline Duration to & Montréal & Paris \\
\hline 5\% recovery (min) & $31.6 \pm 7.0$ & $20.8 \pm 6.5$ \\
& $(21.6-44.9)$ & $(6.2-31.5)$ \\
25\% recovery (min) & $39.1 \pm 7.3$ & $28.5 \pm 6.8$ \\
& $(27.6-58.9)$ & $(12.5-40.5)$ \\
Duration from 5-25\%(min) & $7.5 \pm 1.4$ & $7.7 \pm 1.1$ \\
& $(4.5-14)$ & $(4.7-11.3)$ \\
\hline
\end{tabular}

TABLE IV Effect of neostigmine (mean $\pm \mathrm{SD}$ )

\begin{tabular}{ccc}
\hline$T_{4} / T_{1}$ following neostigmine & Montréal & Paris \\
\hline after $0 \mathrm{~min}(\%)$ & $4 \pm 4$ & $6 \pm 3$ \\
& $(0-21)$ & $(0-11)$ \\
$2 \mathrm{~min}(\%)$ & $41 \pm 11$ & $40 \pm 9$ \\
& $(11-55)$ & $(19-59)$ \\
$5 \mathrm{~min}(\%)$ & $69 \pm 7$ & $68 \pm 7$ \\
& $(55-82)$ & $(49-77)$ \\
$10 \mathrm{~min}(\%)$ & $81 \pm 7$ & $82 \pm 6$ \\
& $(70-91)$ & $(64-91)$ \\
Time to $\mathrm{T}_{4} / \mathrm{T}_{1}=70 \%(\mathrm{~min})$ & $5.6 \pm 1.9$ & $6.3 \pm 2.2$ \\
& $(3.7-10)$ & $(4-12)$ \\
\hline
\end{tabular}

\section{Discussion}

This study shows that the duration of action of vecuronium is longer in Montréal than in Paris. However, when neostigmine was given at the same level of recovery, its effect was the same at both sites. Onset data were more variable than duration measurements, and this probably explains the lack of differences in onset times. The coefficient of variation (standard deviation as a percentage of mean values) was $30-33 \%$ for time to maximum blockade and $18-24 \%$ for duration.

The anaesthetic technique and neuromuscular monitoring were the same for both centres, and they were intended to mimic clinical conditions. Vecuronium was given shortly after induction, and the dose chosen, 0.1 $\mathrm{mg} \cdot \mathrm{kg}^{-1}$, is administered commonly for tracheal intubation and for maintenance of relaxation during the first 30-45 $\mathrm{min}$ of surgery. The shorter duration observed in Paris suggests that the relative resistance recorded earlier with dose-response curves using doses in the range $0.02-0.04 \mathrm{mg} \cdot \mathrm{kg}^{-1}$ also applies to larger doses more commonly used in clinical practice.

Care was taken to control for the various factors which might influence the onset time or duration of neuromuscular blockade. The mode of stimulation and interval between train-of-four patterns was the same. The time between the start of stimulation and injection of the neuromuscular blocker can influence onset time, and to a lesser extent, duration of action. ${ }^{4}$ To avoid this confounding factor, vecuronium was injected shortly (approximately two minutes) after the start of stimulation. The anaesthetic agents were the same in both centres. Endtidal isoflurane concentration $(0.5 \%)$ was measured and kept constant until at least ten minutes after neostigmine administration. The same muscle, the adductor pollicis, was monitored in both locations, and force of contraction was measured in both instances. Both force transducers had a linear response with an accuracy of approximately $\pm 2 \%$. This possible error might be sufficient to affect measurement of time to $100 \%$ blockade, because blockade changes slowly when it approaches $100 \% .^{5,6}$ For this reason, onset times to $50 \%$ and $95 \%$ are probably more reliable. These two measures of onset time were not different between both centres. Duration data are even less likely to be affected by a measurement error. When the $\mathrm{T}_{1}$ of Paris patients had recovered to $25 \%$ of control (at a mean time of $28.5 \mathrm{~min}$ ), subjects studied in Montréal had reached less than $5 \%$ (which was attained at 31.6 min). Such a discrepancy cannot be attributed to the inaccuracy of measuring devices.

No attempt was made to keep core, muscle or skin temperature at any pre-determined level, thus mimicking clinical conditions. Core temperature was not measured systematically in all patients, and was found to be $30-45$ min after induction of anaesthesia, $35.5-36.5^{\circ} \mathrm{C}$ in both centres. Thus, although mild core hypothermia $\left(34-35^{\circ} \mathrm{C}\right)$ might prolong the duration of action of vecuronium, ${ }^{7}$ it is unlikely to have been a factor in the present study. Such levels of hypothermia were obtained only after 45-60 min of active cooling. ${ }^{7}$

It is unlikely that the transatlantic differences reported here are due to differences in the rate of distribution or elimination of vecuronium. Dose-response relationships depend on the initial concentration of the drug, and are relatively independent of disposition processes, unless these are very rapid. A previous study ${ }^{3}$ performed in the same hospitals showed a different dose-response 
curve. In addition, the rate of recovery from 5 to $25 \%$ $\mathrm{T}_{1}$, which reflects the rate of redistribution metabolism and/or elimination of the drug, was the same at both centres, suggesting that altered elimination and/or redistribution are not responsible for the differences in duration. A $30 \%$ difference in the dose-response relationships $^{3}$ and a 10.6 min in duration (this study) could be both explained by a difference in the plasma concentration vs effect relationship. Pharmacokinetic studies conducted on both sides of the Atlantic Ocean ${ }^{8,12}$ indicate that plasma concentrations decrease by approximately $30 \%$ between 28.5 and $39.1 \mathrm{~min}$, i.e., the times corresponding to return of $25 \% \mathrm{~T}_{1}$ in Paris and Montréal respectively. Thus, both the increased duration and increased potency observed in Montréal could be explained by a concentration response relationship shifted to the left. It remains to be seen whether these differences are due to the changes in protein binding, or to true differences in sensitivity at the neuromuscular junction. Such a study would require simultaneous measurement of vecuronium concentrations, both total and free, and twitch height. Given the inter-patient variability, such a pharmacokineticpharmacodynamic study would require a large number of patients.

The duration of action of vecuronium is affected by many factors, such as age, ${ }^{12}$ weight, ${ }^{13,14}$ pregnancy 15,16 and end-organ function. ${ }^{9,10}$ The patients in our study had normal renal and hepatic function, were non-pregnant and had comparable heights and weights. The Montréal subjects were six years younger than the Paris patients. If anything, this should have produced a shorter duration in Montreal. The opposite was observed. The presence of a small end-tidal concentration of isoflurane probably had little effect, because the volatile agent did not have time to equilibrate with muscle tissue. ${ }^{17} \mathrm{~A}$ survey of the literature suggests that the duration of action of vecuronium, $0.1 \mathrm{mg} \cdot \mathrm{kg}^{-1}$, might be more variable with geographical location than the differences between Paris and Montréal might indicate. In non-pregnant, ASA I or II young to middle-aged adults, the duration to $25 \% \mathrm{~T}_{1}$ recovery was reported to be $26-30 \mathrm{~min}$ in Holland, ${ }^{17}$ $32 \mathrm{~min}$ in Austria, ${ }^{16}$ and $27.6 \mathrm{~min}$ in Norway, ${ }^{18}$ close to the value of $28.5 \mathrm{~min}$ reported here for Paris. Durations for the same vecuronium dose given to young adults in North America are somewhat more variable, ranging from 32-37.6 min in New York ${ }^{12-14}$ to $50-54 \mathrm{~min}$ in California ${ }^{9.10}$ (interestingly, 34 min was reported from the same institution, ${ }^{7}$ but from a limited number of subjects). Values of $35.3^{15}$ and approximately $40 \mathrm{~min}^{19}$ were reported in Texas and North Carolina, respectively. These values are close to the $39.1 \mathrm{~min}$ observed in Montreal. The absence of overlap between European and North American values suggests a different potency between each continent. However, we do not suggest that the potency is uniform within each continent.

No difference in onset time could be demonstrated in this study. This is probably because onset times are more variable than durations and because increasing the dose does not change onset time markedly. For example, in one study, ${ }^{18}$ increasing the dose by $50 \%$, from 0.1 $\mathrm{mg} \cdot \mathrm{kg}^{-1}$ to $0.15 \mathrm{mg} \cdot \mathrm{kg}^{-1}$ decreased onset time from 169 to $146 \mathrm{sec}$, and the difference was not statistically significant. In Montréal, the potency of vecuronium was found to be $30 \%$ greater than in Paris, suggesting that the effect of the drug might mimic, in Montréal, that of a dose increased by $30 \%$ in Paris. This small increase in equivalent dose would be expected to produce little change in onset times.

There are few studies of the effect of neostigmine, 0.04 $\mathrm{mg} \cdot \mathrm{kg}^{-1}$, given at $25 \%$ first twitch height recovery after vecuronium. The values of train-of-four ratio reported here for five and ten minutes $(68-69 \%$ and $81-82 \%$ respectively) compare well with the 82 and $84 \%$ reported by a Belgian group ${ }^{20}$ at six and nine minutes respectively under nitrous oxide-narcotic anaesthesia. Addition of 1 MAC isoflurane was found to decrease the $T_{4} / T_{1}$ values by $10-15 \% .^{21}$ In the present study, approximately 0.4 MAC isoflurane was used, and the results are between those obtained with nitrous oxide-narcotic and nitrous oxide-isoflurane anaesthesia. ${ }^{21}$ The effect of neostigmine given at the same twitch height recovery was the same in Montréal and in Paris. This suggests that acetylcholinesterase function and the other mechanisms responsible for reversal of neuromuscular blockade operate similarly at both sites.

In summary, after an intubating dose of vecuronium, Montréal patients behave as if they were more sensitive to the drug than subjects with comparable demographic characteristics in Paris and duration of action is increased. Slight alterations in dosage and management of relaxation might be required. For example, all Paris patients recovered to $25 \% \mathrm{~T}_{1}$ within $45 \mathrm{~min}$ while this level of recovery was not attained in $25 \%$ of Montreal patients. There is, however, no need to modify the dose of neostigmine depending on the site, provided the anticholinesterase drug is administered at $25 \%$ recovery.

\section{References}

1 Katz RL, Norman J, Seed RF, Conrad L. A comparison of the effects of suxamethonium and tubocurarine in patients in London and New York. Br J Anaesth 1969; 41: 1041-7.

2 Ali HH, Utting JE, Gray TC. Quantitative assessment of residual antidepolarizing block (Part I). Br J Anaesth 1971; 43: 473-7.

3 Fiset P, Donati F, Balendran P, Meistelman C, Lira E, 
Bevan DR. Vecuronium is more potent in Montreal than in Paris. Can J Anaesth 1991; 38: 717-21.

4 Curran MJ, Donati F, Bevan DR. Onset and recovery of atracurium and suxamethonium-induced neuromuscular blockade with simultaneous train-of-four and single twitch stimulation. Br J Anaesth 1987; 59: 989-94.

5 Donati $F$. Effect of dose and potency on onset. Anaesthetic Pharmacology Review 1993; 1: 34-43.

6 Koscielniak-Nielsen ZJ, Bevan JC, Popovic V, Baxter $M R N$, Donati $F$, Bevan $D R$. Onset of maximum neuromuscular block following succinylcholine or vecuronium in four age groups. Anesthesioloy 1993; 79: 229-34.

7 Heier T, Caldwell JE, Sessler DI, Miller RD. Mild intraoperative hypothermia increases duration of action and spontaneous recovery of vecuronium blockade during nitrous oxide-isoflurane anesthesia in humans. Anesthesiology 1991; 74: 815-9.

8 Sohn YJ, Bencini AF, Scaf AHJ, Kersten UW, Agoston S. Comparative pharmacokinetics and dynamics of vecuronium and pancuronium in anesthetized patients. Anesth Analg 1986; 65: 233-9.

9 Arden JR, Lynam DP, Castagnoli KP, Canfell PC, Cannon $J C$, Miller $R D$. Vecuronium in alcoholic liver disease: a pharmacokinetic and pharmacodynamic analysis. Anesthesiology 1988; 68: 771-6.

10 Lynam DP, Cronnelly $R$, Castagnoli $K P$, et al. The pharmacodynamics and pharmacokinetics of vecuronium in patients anesthetized with isoflurane with normal renal function or with renal failure. Anesthesiology 1988; 69: 227-31.

11 Ducharme J, Varin $F$, Bevan $D R$, Donati $F$. Importance of early blood sampling on vecuronium pharmacokinetic and pharmacodynamic parameters. Clin Pharmacokinet 1993; 24: 507-18.

12 Lien CA, Matteo RS, Ornstein E, Schwartz AE, Diaz J. Distribution, elimination, and action of vecuronium in the elderly. Anesth Analg 1991; 73: 39-42.

13 Weinstein JA, Matteo RS, Ornstein E, Schwartz AE, Goldstoff $M$, Thal $G$. Pharmacodynamics of vecuronium and atracurium in the obese surgical patient. Anesth Analg 1988; 67: 1149-53.

14 Schwartz AE, Matteo RS, Ornstein E, Halevy JD, Diaz J. Pharmacokinetics and pharmacodynamics of vecuronium in the obese surgical patient. Anesth Analg 1992; 74: 515-8.

15 Camp CE, Tessem J, Adenwala J, Joyce TH III. Vecuronium and prolonged neuromuscular blockade in postpartum patients. Anesthesiology 1987; 67 1006-8.

16 Khuenl-Brady KS, Koller J, Mair P, Pühringer F, Mitterschiffhaler $G$. Comparison of vecuronium- and atracurium-induced neuromuscular blockade in postpartum and nonpregnant patients. Anesth Analg 1991; 72: 110-3.

17 Swen J, Rashkovsky OM, Ket JM, Koot HWJ, Hermans $J$, Agoston $S$. Interaction between nondepolarizing neuro- muscular blocking agents and inhalational anesthetics. Anesth Analg 1989; 69: 752-5.

18 Rørvik K, Husby P, Gramstad L, Vamnes JS, BitschLarsen $L$, Koller $M-E$. Comparison of large dose of vecuronium with pancuronium for prolonged neuromuscular blockade. Br J Anaesth 1988; 61: 180-5.

19 Ginsberg B, Glass PS, Quill T, Shafron D, Ossey KD. Onset and duration of neuromuscular blockade following high-dose vecuronium administration. Anesthesiology 1989; 71: 201-5.

20 Baurain MJ, Dernovoi BS, d'Hollander AA, Barvais $L$. The influence of atropine dose on recovery from vecuronium-induced neuromuscular blockade. Anesthesiology 1992; 77: 17-20.

21 Baurain MJ, d'Hollander AA, Melot C, Dernovoi BS, Barvais $L$. Effects of residual concentrations of isoflurane on the reversal of vecuronium-induced neuromuscular blockade. Anesthesiology 1991; 74: 474-8. 